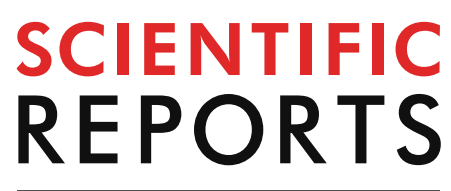

natureresearch

Check for updates

\title{
Effects of pre-oxidation
} on the corrosion behavior of pure Ti under coexistence of solid $\mathrm{NaCl}$ deposit and humid oxygen at $600^{\circ} \mathrm{C}$ : the diffusion of chlorine

\author{
Lei Fan ${ }^{1,3}$, Li Liu ${ }^{2 \bowtie}$, Yuhai Lv ${ }^{4}$, Hao Wang ${ }^{4}$, Anqing Fu ${ }^{1}$, Juntao Yuan ${ }^{1}$, Ying Li ${ }^{3}$, Fuhui Wang ${ }^{2} \&$ \\ Chengxian Yin ${ }^{1}$
}

The effect of pre-oxidation on the corrosion behavior of pure Ti covered with a solid $\mathrm{NaCl}$ deposit in the humid $\mathrm{O}_{2}$ flow at $600^{\circ} \mathrm{C}$ is studied. The oxide scale, formed by pre-oxidation, protects the substrate from the $\mathrm{NaCl}$ induced corrosion during the initial stage. However, the corrosion of the pre-oxidized sample is severely accelerated by solid $\mathrm{NaCl}$ after an incubation period. The chlorine, generated from the decomposition of solid $\mathrm{NaCl}$, diffuses into the oxide/substrate interface as ions during the incubation period, which was observed by ToF-SIMS. The chlorine at the oxide/substrate interface induces the fast corrosion after the incubation period although the pre-oxidation scale is complete and compact.

Compressor blades of airplanes and ships suffer severe corrosion in marine environment, which is mainly due to the fact that marine air contains abundant salts (especially $\mathrm{NaCl}$ ) and water vapor. At the temperature of $300-600^{\circ} \mathrm{C}$ where compressor blades operate, $\mathrm{NaCl}$ appears in solid state and gets deposited on the metal surface. The corrosion of several metals and alloys of compressor blades gets accelerated under a synergistic effect of the solid $\mathrm{NaCl}$ deposit and humid oxygen.

Extensive works have been done on the corrosion behavior of several metals and alloys of compressor blades. The authors in paper ${ }^{1-11}$ demonstrated that the corrosion behavior of pure Fe, pure $\mathrm{Cr}, \mathrm{Fe}-\mathrm{Cr}$ alloy, Ti alloy and $\mathrm{Ni}$ alloy at $600{ }^{\circ} \mathrm{C}$ under a deposit of solid $\mathrm{NaCl}$ deteriorated sharply. Similarly, the authors investigated the influence of $\mathrm{KCl}$ on the oxidation of the 304-type ( $\mathrm{Fe} 18 \mathrm{Cr} 10 \mathrm{Ni}$ ) austenitic stainless steel at $600{ }^{\circ} \mathrm{C}$ in $5 \% \mathrm{O}_{2}$ and in $5 \% \mathrm{O}_{2}+40 \% \mathrm{H}_{2} \mathrm{O}$ in paper ${ }^{12-17}$, and the results showed that small additions of potassium chloride strongly accelerated high temperature corrosion. The fast corrosion is mainly due to a chemical reaction of the solid $\mathrm{NaCl} /$ $\mathrm{KCl}$ deposit with oxides. This reaction destroys the protective oxide scale on the surface and forms a porous nonprotective scale (i.e., the scale has numerous holes and voids ${ }^{1,6,8,9,15,17}$ ). It is also reported in these investigations that the key factor for the fast corrosion is the chlorine, $\mathrm{HCl}$ or $\mathrm{Cl}_{2}$, which cyclically reacts with the substrate at the oxide/substrate interface. The gaseous molecule of chlorine, which is formed during the chemical reaction of solid $\mathrm{NaCl}$ and oxide ${ }^{1,8,18}$, diffuses inward quickly through macro defects (like cracks and holes) in the scale of corrosion products. The chlorine then reacts cyclically with the substrate to generate volatile products (for example $\mathrm{CrCl}_{3}$ ) which break the protective scale ${ }^{1,3,6,8}$.

In our previous work ${ }^{11}$, we observe that the scale of corrosion products of Ti60 alloys can be divided into an outer the corrosion layer and an inner corrosion layer after exposure at $600{ }^{\circ} \mathrm{C}$ in the environment of $\mathrm{NaCl}+\mathrm{H}_{2} \mathrm{O}+\mathrm{O}_{2}$. The chlorine exists in a Ti-Cl bond which is formed by replacing $\mathrm{O}$ with $\mathrm{Cl}$ within lattices of

\footnotetext{
${ }^{1}$ State Key Laboratory for Performance and Structure Safety of Petroleum Tubular Goods and Equipment Materials, CNPC Tubular Goods Research Institute, NO. 89, Jinyeer Rode, Xi'an 710077, Shaanxi, China. ${ }^{2}$ Key Laboratory for Anisotropy and Texture of Materials (MoE), School of Materials Science and Engineering, Northeastern University, NO. 3-11, Wenhua Road, Shenyang 110819, China. ${ }^{3}$ Institute of Metal Research, Chinese Academy of Sciences, NO. 62, Wencui Road, Shenyang 110016, Liaoning, China. ${ }^{4} \mathrm{NO} .1$ Gas Production Plant of Changqing Oilfield Company, Jingbian 718500, Shaanxi, China. ${ }^{\circledR}$ email: liuli@mail.neu.edu.cn
} 


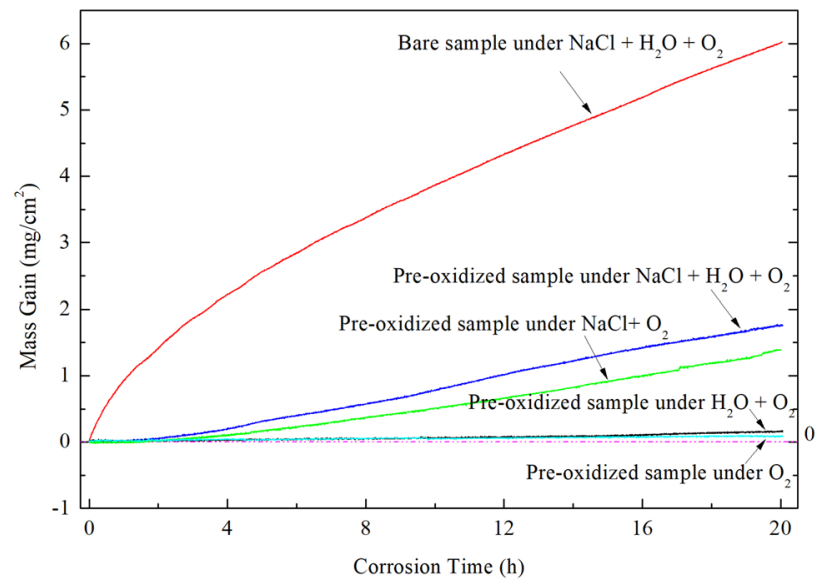

Figure 1. The mass gain curves for the corrosion at $600{ }^{\circ} \mathrm{C}$ of the bare Ti under $\mathrm{NaCl}+\mathrm{H}_{2} \mathrm{O}+\mathrm{O}_{2}$ (red line) and the pre-oxidized Ti under $\mathrm{O}_{2}$ (cyan line), $\mathrm{H}_{2} \mathrm{O}+\mathrm{O}_{2}$ (black line), $\mathrm{NaCl}+\mathrm{O}_{2}$ (green line) and $\mathrm{NaCl}+\mathrm{H}_{2} \mathrm{O}+\mathrm{O}_{2}$ (purple line).

Ti oxides of the inner corrosion layer. We think the chlorine can diffuse inward as ion. In this case, $\mathrm{Cl}^{-}$comes from the decomposition of solid $\mathrm{NaCl}$ and the residual sodium reacts with oxides on the surface to form metallic acid salts (like $\mathrm{Na}_{2} \mathrm{CrO}_{4}{ }^{1}$ and $\mathrm{Na}_{4} \mathrm{Ti}_{5} \mathrm{O}_{12}{ }^{10}$ ). In order to make clear the corrosion mechanism, we need to first figure out the state of the chlorine and study its diffusion in the scale of corrosion products, especially during the destruction process of the scale of protective oxide, like $\mathrm{TiO}_{2}$ and $\mathrm{Cr}_{2} \mathrm{O}_{3}$.

When pure $\mathrm{Ti}$ is oxidized in the pure $\mathrm{O}_{2}$ condition at $600{ }^{\circ} \mathrm{C}$, a compact and even oxide scale forms on the surface ${ }^{10}$. This oxide scale can simulate the passive film to protect the substance from the corrosive environment. When the pre-oxidized pure $\mathrm{Ti}$ is exposed in the $\mathrm{NaCl}+\mathrm{H}_{2} \mathrm{O}+\mathrm{O}_{2}$ environment, this oxide scale can slow down the destruction process of the protective passive film such that the behavior of the solid $\mathrm{NaCl}$ can be investigated in detail. Thus, to clarify the micro-mechanism under the specific environment of $\mathrm{NaCl}+\mathrm{H}_{2} \mathrm{O}+\mathrm{O}_{2}$, we need to study the effects of pre-oxidation on the corrosion behavior of pure Ti.

In this paper, we investigate the effects of pre-oxidation on the corrosion behavior of pure Ti underneath a solid $\mathrm{NaCl}$ deposit in humid $\mathrm{O}_{2}$ flow at $600{ }^{\circ} \mathrm{C}$, using scanning electron microscope (SEM) equipped with an energy dispersive spectrometer (EDS), X-ray diffraction (XRD) and time of flight-secondary ion mass spectrometry (ToF-SIMS). After examining the detailed properties of the corrosion products and the diffusion of chlorine in the oxide scale, we discuss possible micro acceleration mechanisms of the chlorine based on experiment results.

\section{Result}

Corrosion kinetics. The mass gain curves of pure Ti under different conditions are shown in Fig. 1. For the pre-oxidized samples, the mass gain under the condition of $\mathrm{H}_{2} \mathrm{O}+\mathrm{O}_{2}\left(\right.$ about $0.17 \mathrm{mg} / \mathrm{cm}^{2}$ ) is slightly larger than that under the condition of $\mathrm{O}_{2}$ (about $0.09 \mathrm{mg} / \mathrm{cm}^{2}$ ). In fact, under both the above two conditions the corrosion is minor. In the initial stage (incubation period), the mass gain is slight when the pre-oxidized pure Ti samples under $\mathrm{NaCl}$ deposit. In contrast, the mass gain increases rapidly after this incubation period. After $20 \mathrm{~h}$ exposure in $\mathrm{NaCl}+\mathrm{H}_{2} \mathrm{O}+\mathrm{O}_{2}$ or $\mathrm{NaCl}+\mathrm{O}_{2}$, the mass gains are about $1.8 \mathrm{mg} / \mathrm{cm}^{2}$ and $1.4 \mathrm{mg} / \mathrm{cm}^{2}$, respectively, which are about one order of magnitude larger than that in the absence of the solid $\mathrm{NaCl}$ deposit. Thus, we reach the conclusion that the solid $\mathrm{NaCl}$ accelerates the corrosion of the pre-oxidized pure $\mathrm{Ti}$ in $\mathrm{O}_{2}$ or humid $\mathrm{O}_{2}$.

For the bare samples, the mass gain increases dramatically during the whole exposure in $\mathrm{NaCl}+\mathrm{H}_{2} \mathrm{O}+\mathrm{O}_{2}$. After exposed for $20 \mathrm{~h}$, the mass gain is about $6.0 \mathrm{mg} / \mathrm{cm}^{2}$, which is increased by 3.5 times compared with the pre-oxidized samples. Therefore, we can conclude that the pre-oxidation improves the corrosion resistance of pure Ti coated with a solid $\mathrm{NaCl}$ deposit in humid $\mathrm{O}_{2}$ at $600{ }^{\circ} \mathrm{C}$, especially in the incubation period.

Phase composition and microstructure of the pre-oxidized sample. For the pure Ti samples after pre-oxidation in $\mathrm{O}_{2}$ flow for $20 \mathrm{~h}$, the surface and the cross-sectional morphologies are shown in Fig. 2. As can be observed in Fig. 2a,b, a continuous, compact and even oxide scale is formed on the surface. The thickness of the oxide scale is about $1 \mu \mathrm{m}$ (Fig. 2b). We show the results of EDS analysis on the oxide scale in Fig. 2c. As can be seen, it consists of Ti and O. Through XRD analysis (which is not shown here), the phase composition of the pre-oxidized sample surface is only $\mathrm{TiO}_{2}$.

Phase composition and microstructure of the hot corrosion products forming on the bare samples. For the bare samples after $20 \mathrm{~h}$ exposure in $\mathrm{NaCl}+\mathrm{H}_{2} \mathrm{O}+\mathrm{O}_{2}$, the surface and the cross-sectional morphologies are shown in Fig. 3. As can be observed, the scale of corrosion products contains two parts: one with a compact structure, and the other with a grid structure part. The corrosion products with a compact structure (marked in Fig. 3a,b) are very complete, uniform and compact. The corrosion products with a grid structure 


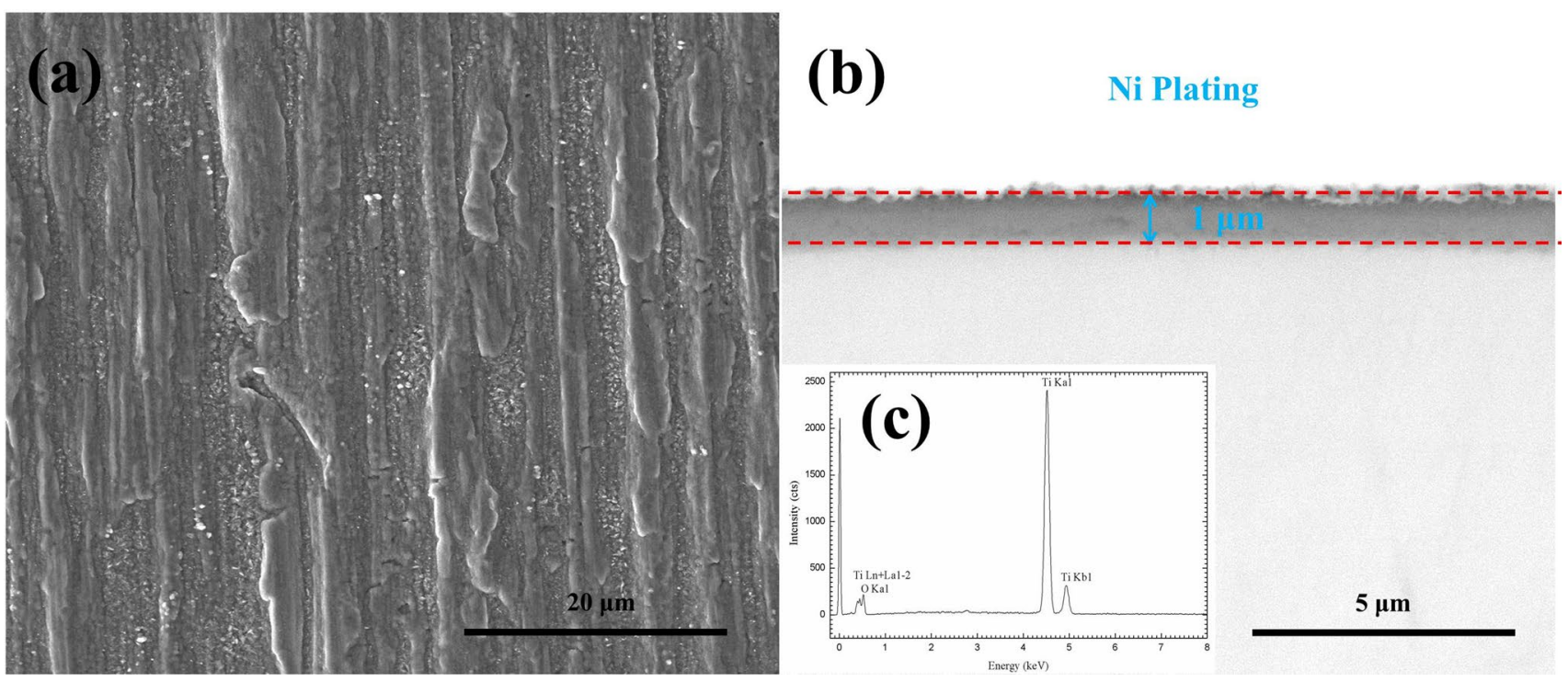

Figure 2. Surface morphologies (a), cross-sectional morphologies (b) and EDS patterns (c) of pure Ti oxidized in dry $\mathrm{O}_{2}$ at $600{ }^{\circ} \mathrm{C}$ for $20 \mathrm{~h}$.
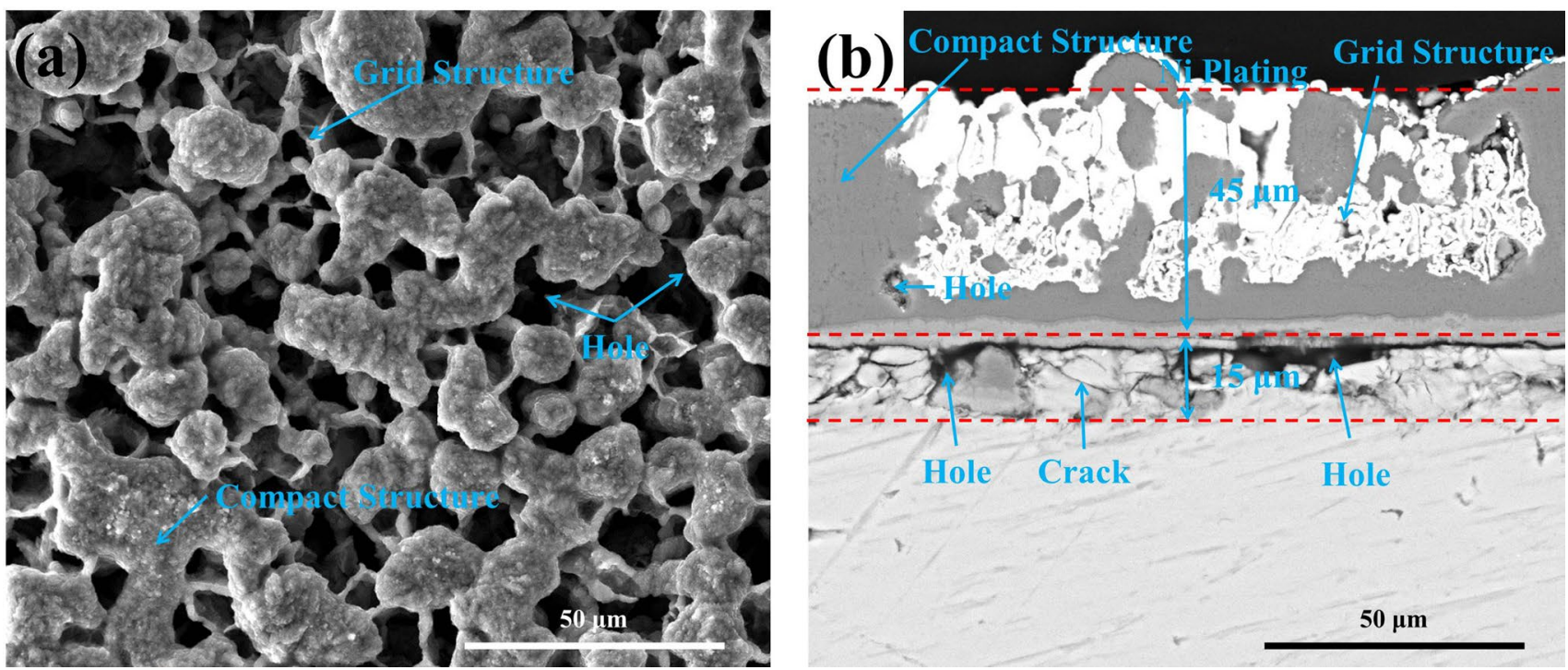

Figure 3. Surface morphologies (a) and cross-sectional morphologies (b) of the bare samples after corrosion in $\mathrm{NaCl}+\mathrm{H}_{2} \mathrm{O}+\mathrm{O}_{2}$ at $600{ }^{\circ} \mathrm{C}$ for $20 \mathrm{~h}$.

(marked in Fig. 3a,b) contain lots of holes (filled with Ni plating as shown in Fig. 3b), which penetrate the corrosion scale. These through-holes are the fast diffusion path for the corrosion medium. Below the corrosion scale, a loose layer, containing some holes (close pores) and cracks, is formed within the substrate due to the outward diffusion of Ti. The thickness of the corrosion product scale and the loose layer is about $45 \mu \mathrm{m}$ and 15 $\mu \mathrm{m}$, respectively.

In Fig. 4, we present the XRD patterns of the bare samples exposed in $\mathrm{NaCl}+\mathrm{H}_{2} \mathrm{O}+\mathrm{O}_{2}$ up to $20 \mathrm{~h}$. The results show that the corrosion products mainly consist of $\mathrm{TiO}_{2}$ and some $\mathrm{Na}_{4} \mathrm{Ti}_{5} \mathrm{O}_{12}$, with the residual $\mathrm{NaCl}$.

Phase composition and microstructure of the hot corrosion products forming on the pre-oxidized samples. For the pre-oxidized pure Ti samples after $100 \mathrm{~h}$ exposure in dry $\mathrm{O}_{2}$ flow, the surface and the cross-sectional morphologies are shown in Fig. 5. As can be seen in Fig. 5a,b, a very thin, compact and continuous scale is formed on the pre-oxidized samples after $100 \mathrm{~h}$ exposure in dry $\mathrm{O}_{2}$ flow. From Fig. 5c, we can see that the thickness of the oxide scale is about $2.5 \mu \mathrm{m}$.

For the pre-oxidized samples after $100 \mathrm{~h}$ exposure in humid $\mathrm{O}_{2}$ flow, the surface and the cross-sectional morphologies are presented in Fig. 6. As can be observed from Fig. 6a,b, a very thin, compact and continuous scale which contains both granulated corrosion products and compact products was formed on the pre-oxidized 


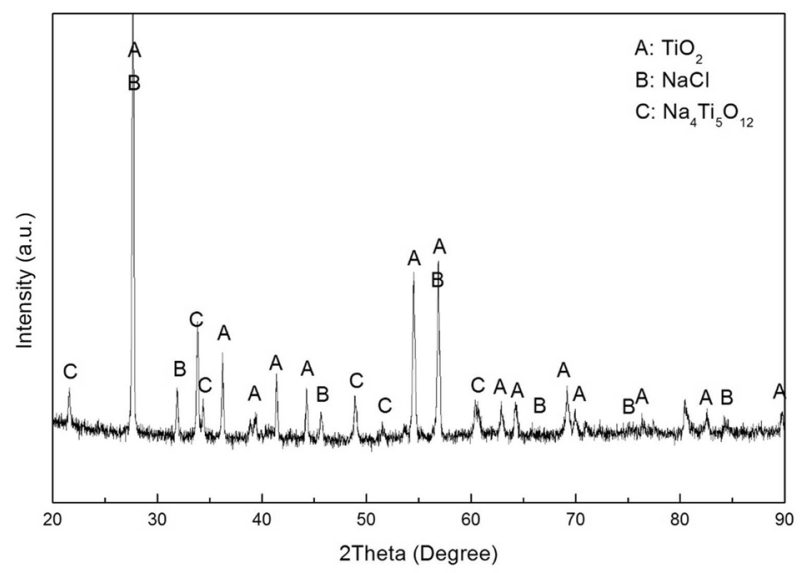

Figure 4. X-ray diffraction patterns of the bare samples exposed in $\mathrm{NaCl}+\mathrm{H}_{2} \mathrm{O}+\mathrm{O}_{2}$ up to $20 \mathrm{~h}$ at $600{ }^{\circ} \mathrm{C}$.

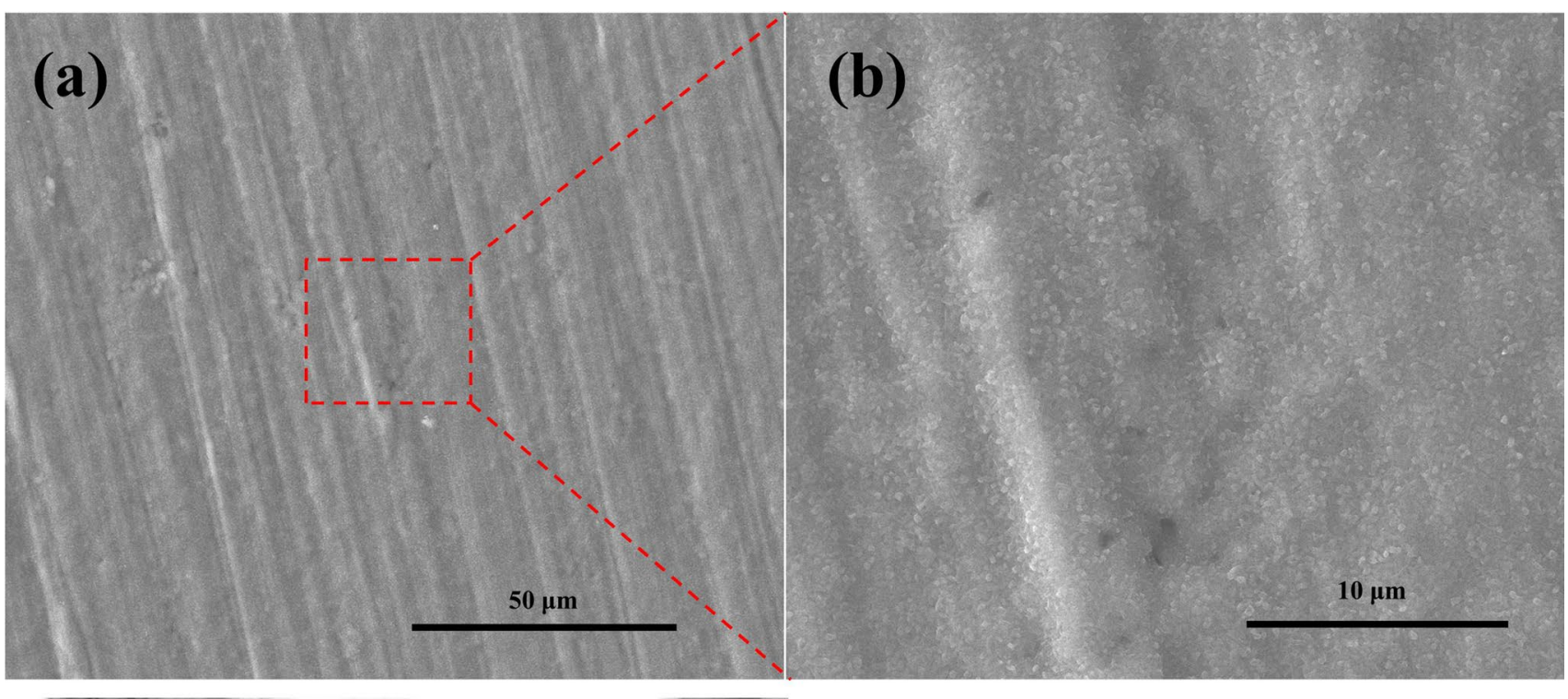

(c) Ni Plating

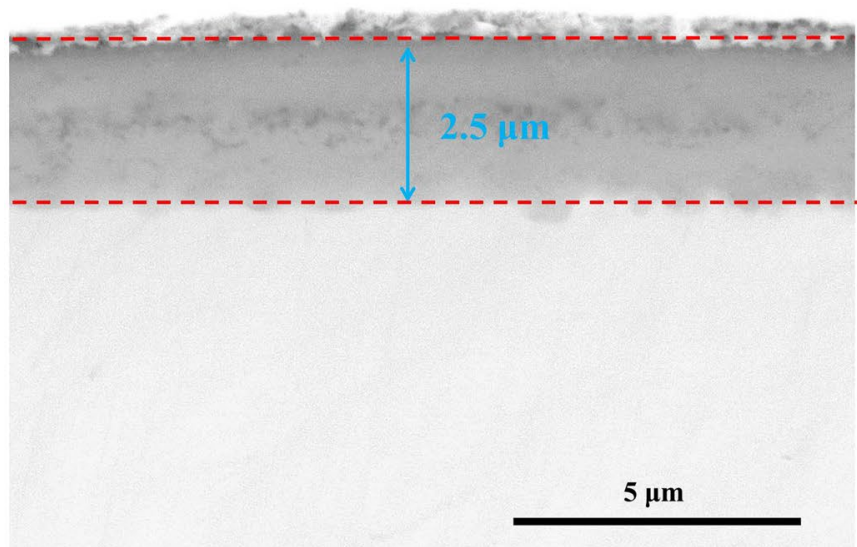

Figure 5. Surface morphologies (a), the high magnification image (b) and cross-sectional morphologies (c) of the pre-oxidized samples after oxidized in dry $\mathrm{O}_{2}$ at $600{ }^{\circ} \mathrm{C}$ for $100 \mathrm{~h}$. 

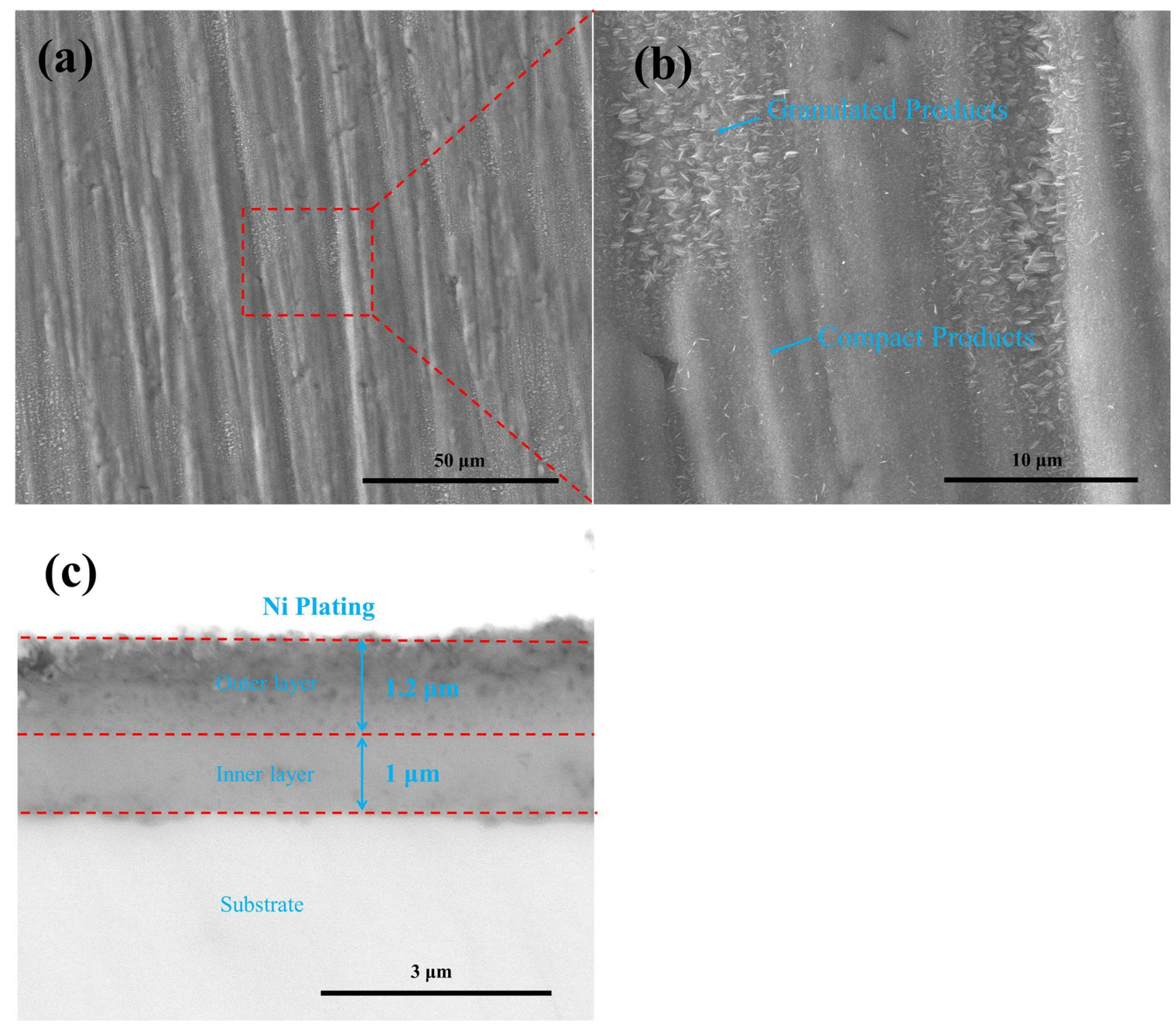

Figure 6. Surface morphologies (a), the high magnification image (b) and cross-sectional morphologies (c) of the pre-oxidized samples after oxidized in humid $\mathrm{O}_{2}$ at $600{ }^{\circ} \mathrm{C}$ for $100 \mathrm{~h}$.

samples. From Fig. 6c, we can see that the oxide scale is divided into a loose outer layer and a compact inner layer, with a thickness of about $1.2 \mu \mathrm{m}$ and $1 \mu \mathrm{m}$, respectively.

For the pre-oxidized samples after $20 \mathrm{~h}$ exposure in $\mathrm{NaCl}+\mathrm{O}_{2}$, the surface and the cross-sectional morphologies are displayed in Fig. 7. As can be seen in Fig. 7a, the corrosion products on the surface are in clusters. As can be observed in Fig. 7b,c, the corrosion product scale can be divided into an outer layer and an inner layer. The outer layer is filled with clustered corrosion products, and the inner layer whose thickness is about $5 \mu \mathrm{m}$ contains loose corrosion products.

For the pre-oxidized samples after $20 \mathrm{~h}$ exposure in $\mathrm{NaCl}+\mathrm{H}_{2} \mathrm{O}+\mathrm{O}_{2}$, the surface and the cross-sectional morphologies are depicted in Fig. 8. As can be observed in Fig. 8a,b, corrosion products have a very thin, compact and continuous scale, with some blind holes forming on the surface where we can also observe some defects (like pore). Furthermore, the scale can be divided into a loose inner corrosion layer and a compact outer corrosion layer. As shown in Fig. 8c, the thickness of the outer corrosion layer and the inner corrosion layer is $8 \mu \mathrm{m}$ and $10 \mu \mathrm{m}$, respectively.

For the pre-oxidized samples after $1 \mathrm{~h}$ exposure in $\mathrm{NaCl}+\mathrm{H}_{2} \mathrm{O}+\mathrm{O}_{2}$, the surface and the cross-sectional morphologies are shown in Fig. 9. From Fig. 9a, we can observe a compact scale on which some loose corrosion products are scattered. In Fig. 9b, we can observe that under the loose product, the scale still remains complete and compact. This implies that the loose products are formed due to the reaction of the outward diffusion metal ions with the corrosive species. From Fig. 9d, we can observe that the thickness of this scale is about $1 \mu \mathrm{m}$.

For the pre-oxidized samples after $5 \mathrm{~h}$ exposure in $\mathrm{NaCl}+\mathrm{H}_{2} \mathrm{O}+\mathrm{O}_{2}$, the surface and the cross-sectional morphologies are depicted in Fig. 10. From Fig. 10a, we can observe that the porous corrosion products spread over the entire surface. This is consistent with the fact in Fig. 1 that the mass gain increased rapidly after the 

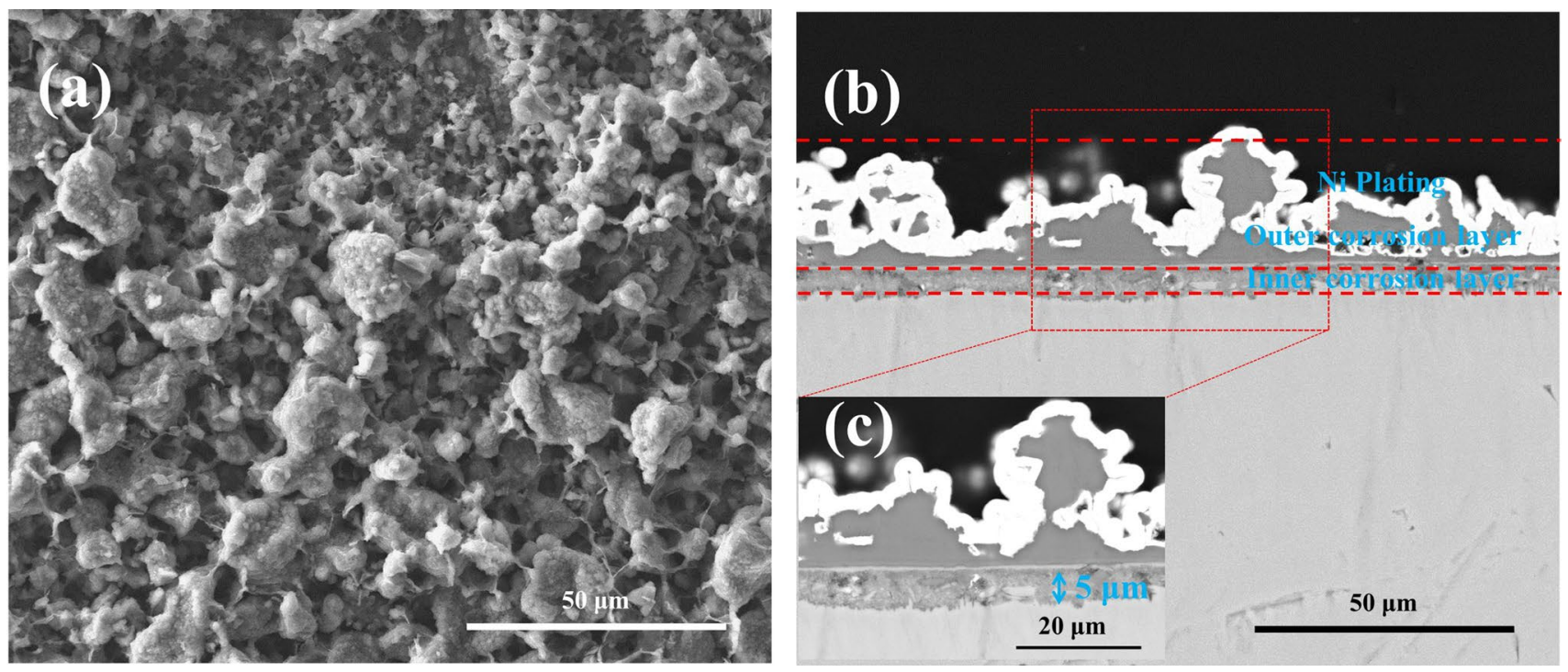

Figure 7. Surface morphologies (a) and cross-sectional morphologies (b) and the high magnification image (c) of the pre-oxidized samples after corrosion in $\mathrm{NaCl}+\mathrm{O}_{2}$ at $600{ }^{\circ} \mathrm{C}$ for $20 \mathrm{~h}$.
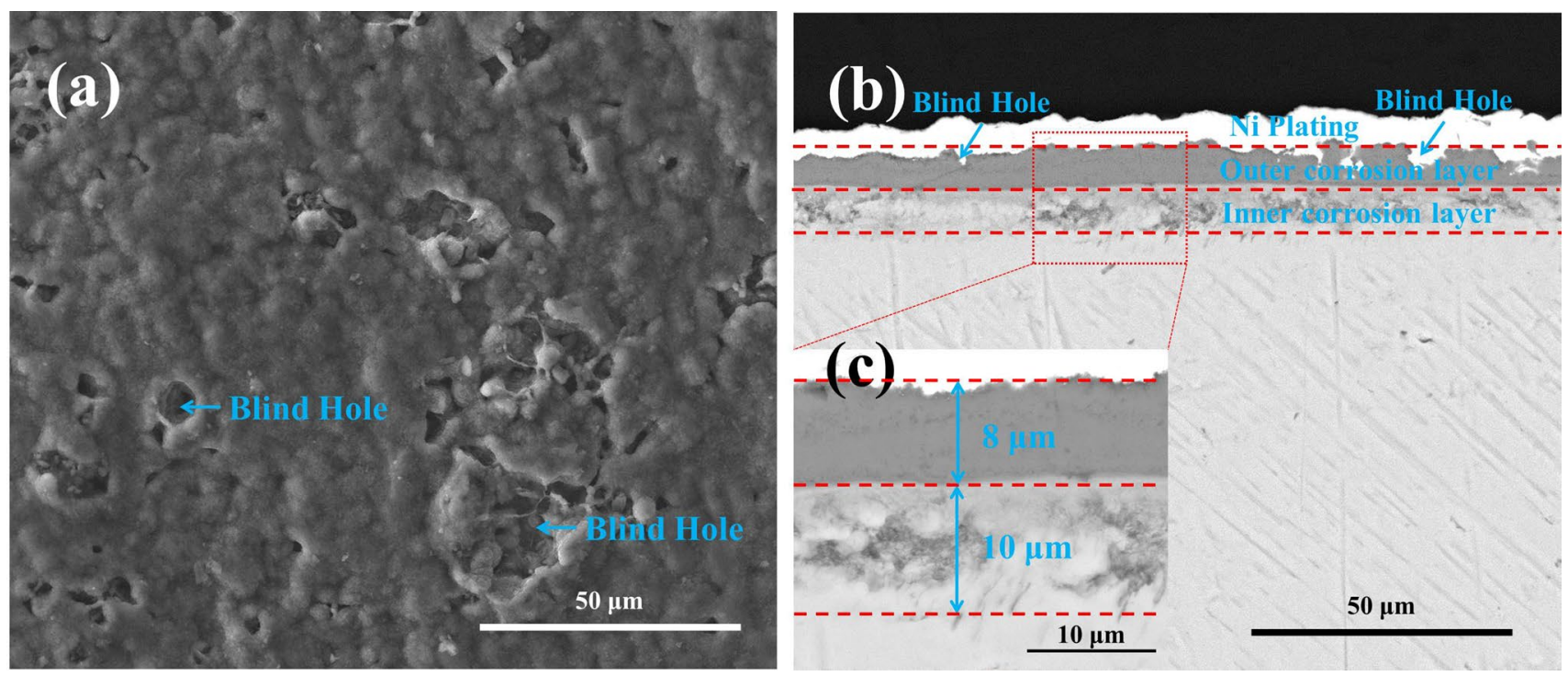

Figure 8. Surface morphologies (a) and cross-sectional morphologies (b) and the high magnification image (c) of the pre-oxidized samples after corrosion in $\mathrm{NaCl}+\mathrm{H}_{2} \mathrm{O}+\mathrm{O}_{2}$ at $600{ }^{\circ} \mathrm{C}$ for $20 \mathrm{~h}$.

incubation period and the corrosion is severe. From Fig. 10b, we can observe that the scale of the corrosion products is compact and its thickness is about $1.2 \mu \mathrm{m}$. We can also observe some loose parts at the interface between the scale and metal.

The corrosion products of the pure Ti samples are identified by XRD. The XRD patterns in Fig. 11 show that only $\mathrm{TiO}_{2}$ was formed on the pre-oxidized samples after $100 \mathrm{~h}$ exposure in dry $\mathrm{O}_{2}$ flow (Fig. 11a) or in $\mathrm{H}_{2} \mathrm{O}+\mathrm{O}_{2}$ flow (Fig. 11b). In Fig. 12, we can observe that the corrosion products are $\mathrm{TiO}_{2}, \mathrm{Ti}_{2} \mathrm{O}$ and $\mathrm{Na}_{4} \mathrm{Ti}_{5} \mathrm{O}_{12}$ on the preoxidized samples after $20 \mathrm{~h}$ exposure in $\mathrm{NaCl}+\mathrm{O}_{2}$ (Fig. 12b), whereas the $\mathrm{Na}_{4} \mathrm{Ti}_{5} \mathrm{O}_{12}$ cannot be identified by XRD after $5 \mathrm{~h}$ exposure (Fig. 12a). As shown in Fig. 13c, after the pre-oxidized samples are exposed in $\mathrm{NaCl}+\mathrm{H}_{2} \mathrm{O}+\mathrm{O}_{2}$ for $20 \mathrm{~h}$, the corrosion products contain both $\mathrm{TiO}_{2}$ and $\mathrm{Na}_{4} \mathrm{Ti}_{5} \mathrm{O}_{12}$. There still remains residual $\mathrm{NaCl}$ as well as the substrate (pure Ti) on the surface. As shown in Fig. 13b, after $5 \mathrm{~h}$ exposure in $\mathrm{NaCl}+\mathrm{H}_{2} \mathrm{O}+\mathrm{O}_{2}$ (which is after the incubation period), the corrosion products also contain $\mathrm{Na}_{4} \mathrm{Ti}_{5} \mathrm{O}_{12}$. Since the diffracted intensity of $\mathrm{Na}_{4} \mathrm{Ti}_{5} \mathrm{O}_{12}$ in Fig. 13c are larger than that in Fig. 13b, we can infer that more $\mathrm{Na}_{4} \mathrm{Ti}_{5} \mathrm{O}_{12}$ is formed when the pre-oxidized samples are exposed in $\mathrm{NaCl}+\mathrm{H}_{2} \mathrm{O}+\mathrm{O}_{2}$ for a longer time period. As shown in Fig. 13a, after $1 \mathrm{~h}$ exposure in $\mathrm{NaCl}+\mathrm{H}_{2} \mathrm{O}+\mathrm{O}_{2}$ (which is during the incubation period), there are not $\mathrm{Na}_{4} \mathrm{Ti}_{5} \mathrm{O}_{12}$ among the corrosion products. We conclude the corrosion products under the above different conditions in Table 1. 


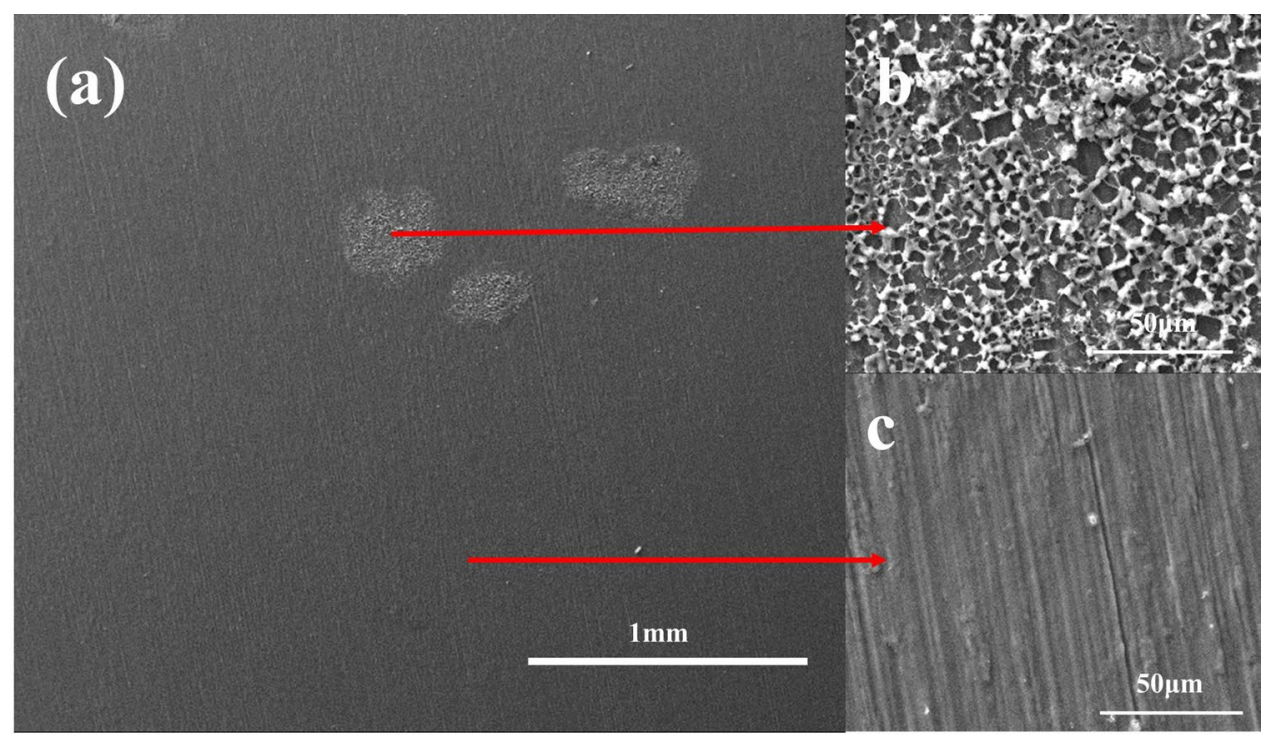

(d)

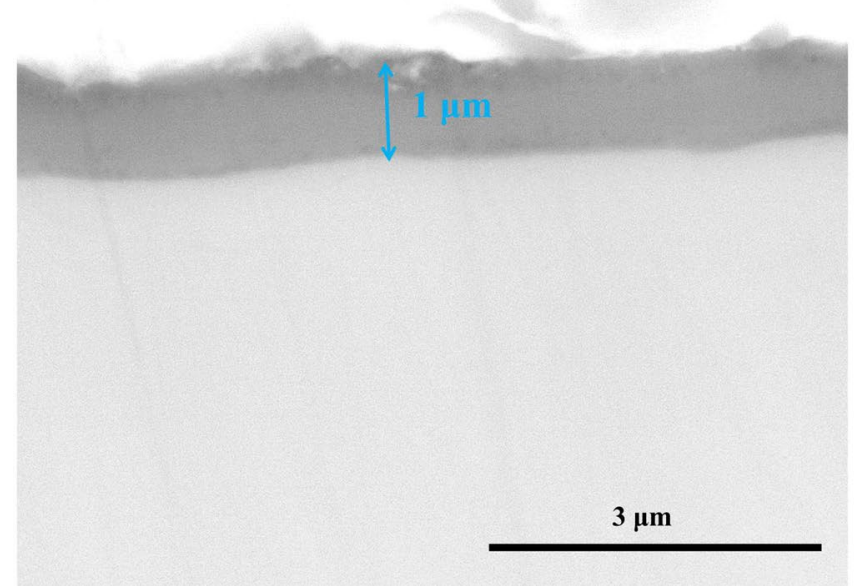

Figure 9. Surface morphologies (a), the high magnification image (b, c) and cross-sectional morphologies (d) of the pre-oxidized samples under a solid $\mathrm{NaCl}$ deposit layer in humid $\mathrm{O}_{2}$ for $1 \mathrm{~h}$ at $600{ }^{\circ} \mathrm{C}$.

Time of flight-secondary ion mass spectrometry, ToF-SIMS. Figure 14 shows the depth profiles for the negative ions from the pre-oxidized samples after $1 \mathrm{~h}$ and $5 \mathrm{~h}$ exposure in $\mathrm{NaCl}+\mathrm{H}_{2} \mathrm{O}+\mathrm{O}_{2}$. The $\mathrm{O}_{2}^{-}$ion signal in Fig. 14 is applied here to indicate the distribution of oxygen in the scale and to identify the interface between the corrosion products scale and the substrate. In Fig. 14a, the $\mathrm{O}_{2}^{-}$ion exhibits two levels of concentration, and the transition region is around the interface of the corrosion product scale and the substrate. Therefore, the average of logarithmic value is pinpointed as the interface as shown in Fig. 14a. Similarly, this interface is also identified in Fig. 14b.

In Fig. 14a, we can also observe that after $1 \mathrm{~h}$ exposure in $\mathrm{NaCl}+\mathrm{H}_{2} \mathrm{O}+\mathrm{O}_{2}, \mathrm{Cl}^{-}$ions first enrich on the surface of the pre-oxidized samples (which was caused by the residual $\mathrm{NaCl}$ ) and then decrease rapidly in the corrosion product scale. Afterwards, $\mathrm{Cl}^{-}$is enriched at the oxide/metal interface, which indicates that the chlorine penetrates the oxide and accumulates at the oxide/metal interface. In Fig. 14b, after the pre-oxidized samples are exposed in $\mathrm{NaCl}+\mathrm{H}_{2} \mathrm{O}+\mathrm{O}_{2}$ for $5 \mathrm{~h}$, a similar distribution of $\mathrm{Cl}^{-}$in the corrosion product scale was observed. Particularly, the $\mathrm{Cl}^{-}$ion is still enriched when the $\mathrm{O}_{2}^{-}$ion decreases around the oxide/metal interface, which implies that some chlorine diffuses into the metal substrate. The intensity of $\mathrm{Cl}^{-}$around the oxide/metal interface is stronger in Fig. 14b than that in Fig. 14a. This implies that more chlorine penetrates into the oxide after a longer exposure in the presence of solid $\mathrm{NaCl}$.

The $\mathrm{OH}^{-}$signal in Fig. 14 is applied here to indicate the distribution of $\mathrm{H}$ in the scale. From Fig. 14a, the distribution of the $\mathrm{OH}^{-}$is similar with $\mathrm{Cl}^{-}$. First, the $\mathrm{OH}^{-}$ion enriches on the surface and then decrease rapidly in the corrosion product scale. This is the information of water vapor. Afterwards, $\mathrm{OH}^{-}$is enriched at the oxide/ metal interface where $\mathrm{Cl}^{-}$is accumulated, which indicates that the $\mathrm{H}$ penetrates the oxide along with the chlorine. 


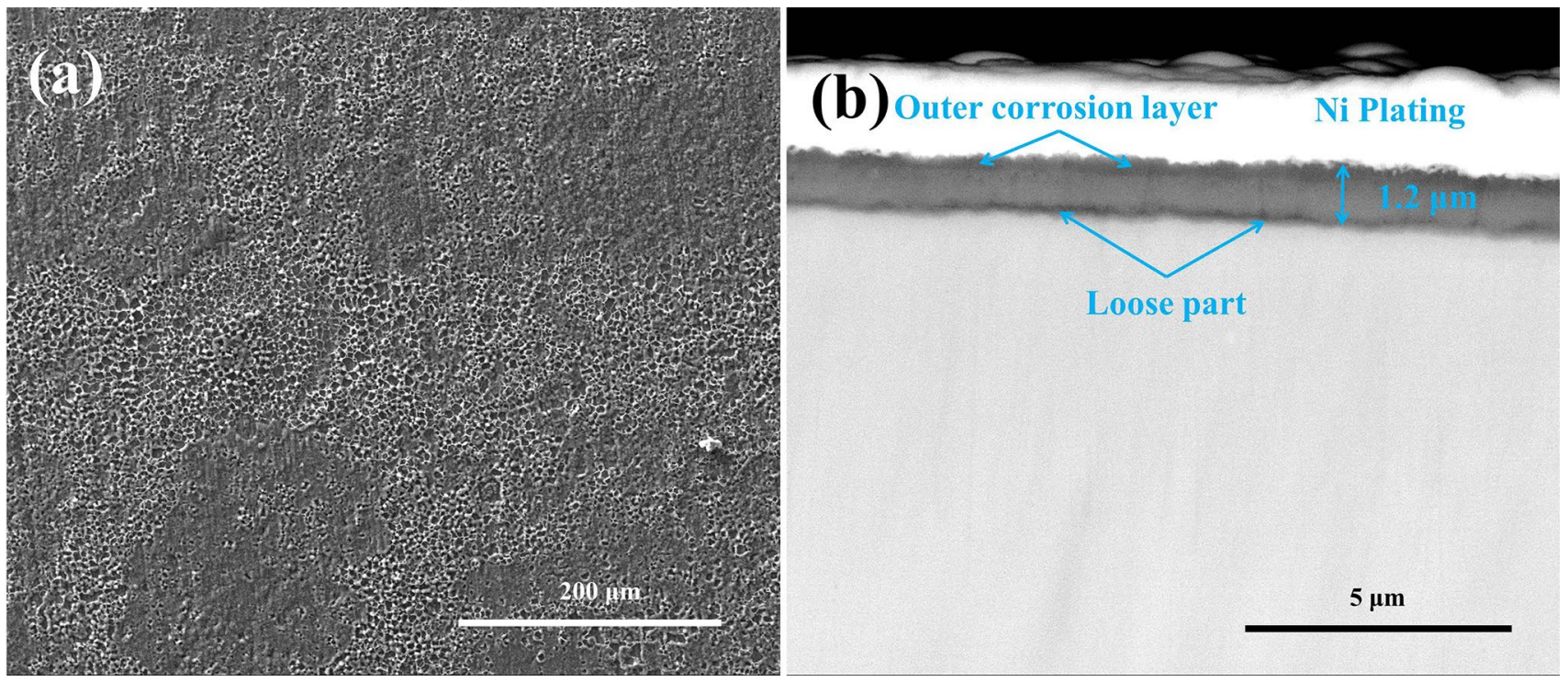

Figure 10. Surface morphologies (a) and cross-sectional morphologies (b) of the pre-oxidized samples under a solid $\mathrm{NaCl}$ deposit layer in humid $\mathrm{O}_{2}$ for $5 \mathrm{~h}$ at $600{ }^{\circ} \mathrm{C}$.
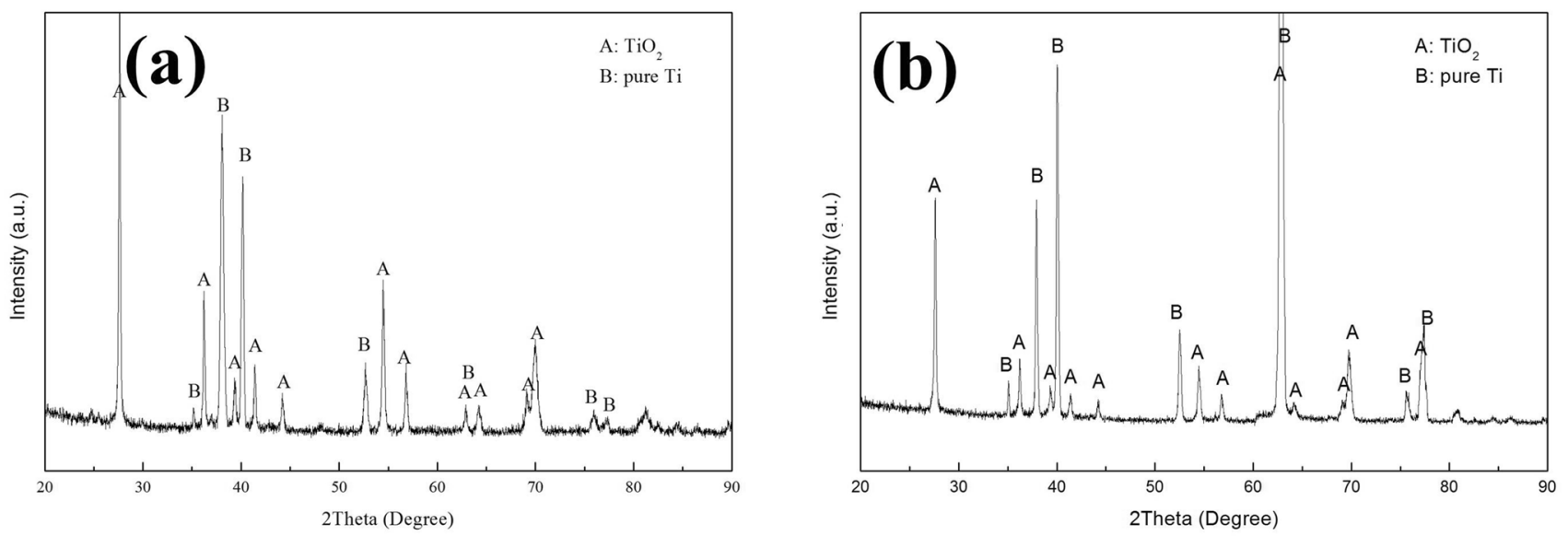

Figure 11. X-ray diffraction patterns of the pre-oxidized samples after exposed in dry $\mathrm{O}_{2}$ flow (a) and in humid $\mathrm{O}_{2}$ flow (b) for $100 \mathrm{~h}$.
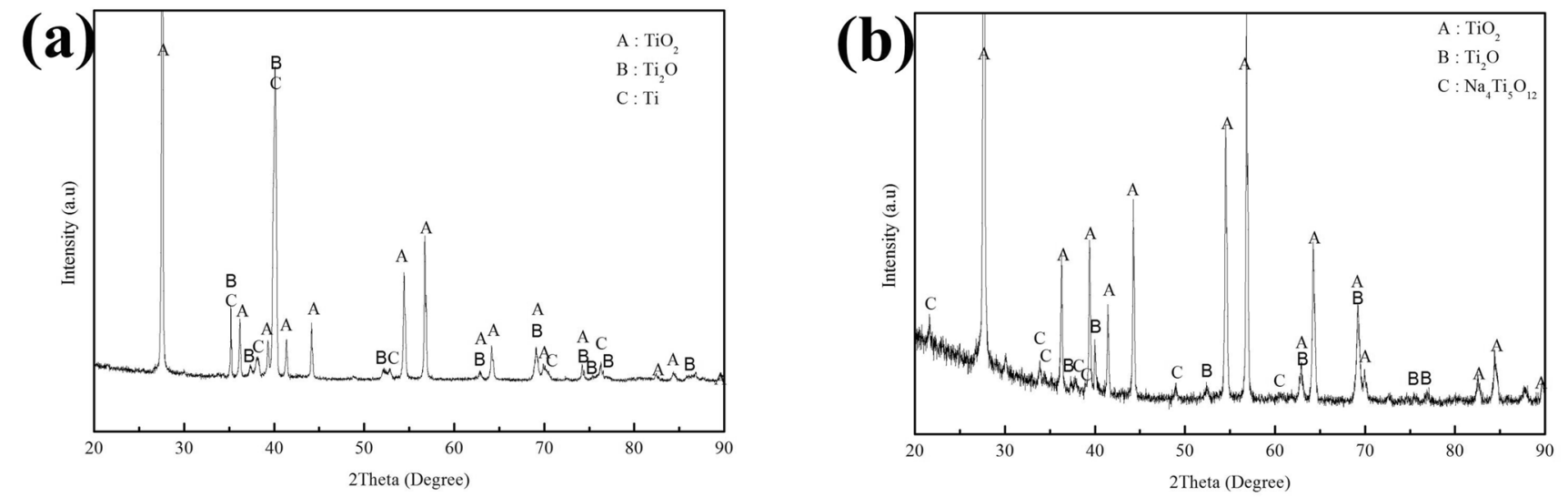

Figure 12. X-ray diffraction patterns of the pre-oxidized samples after exposed in $\mathrm{NaCl}+\mathrm{O}_{2}$ for $5 \mathrm{~h}$ (a) and for $20 \mathrm{~h} \mathrm{(b).}$ 

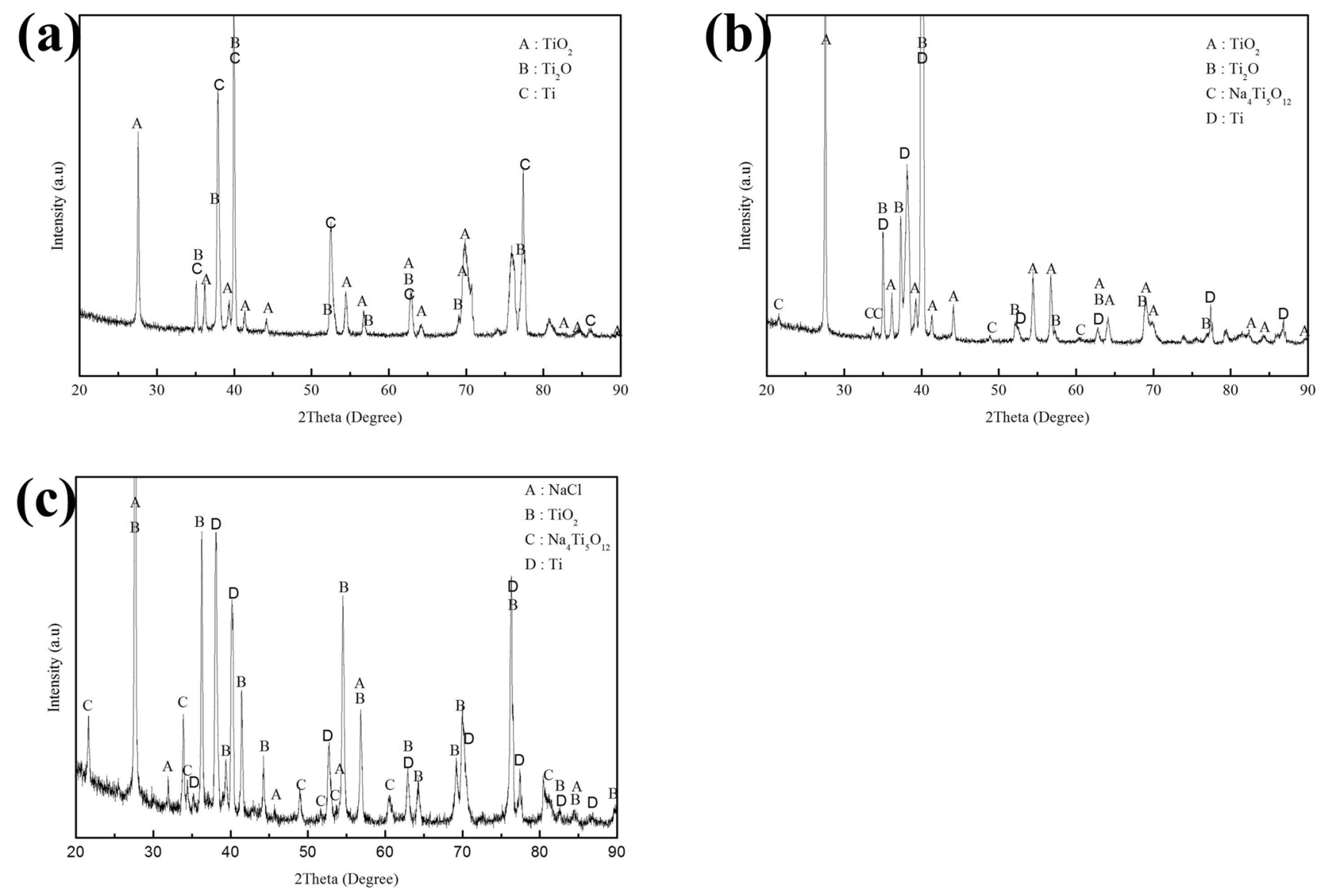

Figure 13. X-ray diffraction patterns of the pre-oxidized samples after exposed in $\mathrm{NaCl}+\mathrm{H}_{2} \mathrm{O}+\mathrm{O}_{2}$ for $1 \mathrm{~h}$ (a), $5 \mathrm{~h} \mathrm{(b)}$ and $20 \mathrm{~h} \mathrm{(c).}$

\begin{tabular}{|c|c|c|c|c|c|}
\hline \multirow[b]{2}{*}{ Samples } & \multirow[b]{2}{*}{ Environment } & \multicolumn{4}{|c|}{ Corrosion time } \\
\hline & & $1 \mathrm{~h}$ & $5 \mathrm{~h}$ & $20 \mathrm{~h}$ & $100 \mathrm{~h}$ \\
\hline Bare samples & $\mathrm{NaCl}+\mathrm{H}_{2} \mathrm{O}+\mathrm{O}_{2}$ & - & - & $\mathrm{TiO}_{2}, \mathrm{Na}_{4} \mathrm{Ti}_{5} \mathrm{O}_{12}$ & - \\
\hline \multirow{4}{*}{ Pre-oxidized samples } & $\mathrm{NaCl}+\mathrm{H}_{2} \mathrm{O}+\mathrm{O}_{2}$ & $\mathrm{TiO}_{2}, \mathrm{Ti}_{2} \mathrm{O}$ & $\mathrm{TiO}_{2}, \mathrm{Ti}_{2} \mathrm{O}, \mathrm{Na}_{4} \mathrm{Ti}_{5} \mathrm{O}_{12}$ & $\mathrm{TiO}_{2}, \mathrm{Ti}_{2} \mathrm{O}, \mathrm{Na}_{4} \mathrm{Ti}_{5} \mathrm{O}_{12}$ & - \\
\hline & $\mathrm{NaCl}+\mathrm{O}_{2}$ & - & $\mathrm{TiO}_{2}, \mathrm{Ti}_{2} \mathrm{O}$ & $\mathrm{TiO}_{2}, \mathrm{Ti}_{2} \mathrm{O}, \mathrm{Na}_{4} \mathrm{Ti}_{5} \mathrm{O}_{12}$ & - \\
\hline & $\mathrm{H}_{2} \mathrm{O}+\mathrm{O}_{2}$ & - & - & - & $\mathrm{TiO}_{2}$ \\
\hline & $\mathrm{O}_{2}$ & - & - & - & $\mathrm{TiO}_{2}$ \\
\hline
\end{tabular}

Table 1. Corrosion products forming on the bare samples and the pre-oxidized samples after hot corrosion.

\section{Discussion}

The acceleration of $\mathrm{NaCl}$ to the corrosion of pure Ti. As shown in Fig. 2, after pure Ti samples were oxidized in the pure $\mathrm{O}_{2}$ flow at $600{ }^{\circ} \mathrm{C}$ for $20 \mathrm{~h}$, a compact $\mathrm{TiO}_{2}$ scale with a thickness of about $1 \mu \mathrm{m}$ was formed on the surface, which is caused by the following reaction between the metal substrate and $\mathrm{O}_{2}$ :

$$
\mathrm{Ti}+\mathrm{O}_{2}=\mathrm{TiO}_{2}
$$

In contrary, the mass gain of pure $\mathrm{Ti}$ under a solid $\mathrm{NaCl}$ deposit layer $\left(\mathrm{NaCl}+\mathrm{H}_{2} \mathrm{O}+\mathrm{O}_{2}\right)$ increased quickly and the mass gain is about $6.0 \mathrm{mg} / \mathrm{cm}^{2}$ after $20 \mathrm{~h}$ exposure (Fig. 1), which is much larger than that in the absence of solid $\mathrm{NaCl}$ (about $0.3 \mathrm{mg} / \mathrm{cm}^{210}$ ). The resulting scale consists of plentiful and porous corrosion products (Fig. 3) and its thickness is about $45 \mu \mathrm{m}$. The above phenomena indicate that pure Ti suffered severe corrosion when exposed in $\mathrm{NaCl}+\mathrm{H}_{2} \mathrm{O}+\mathrm{O}_{2}$. This severe corrosion has been discussed in our previous work ${ }^{10}$ and the main reason is that the protective $\mathrm{TiO}_{2}$ scale cannot be formed due to the occurrence of a series of chemical reactions, and the corrosion becomes active. In the previous mechanism, $\mathrm{NaCl}$ first destroys the protective scale as follow:

$$
5 \mathrm{TiO}_{2}+4 \mathrm{NaCl}+2 \mathrm{H}_{2} \mathrm{O}=\mathrm{Na}_{4} \mathrm{Ti}_{5} \mathrm{O}_{12}+4 \mathrm{HCl}
$$



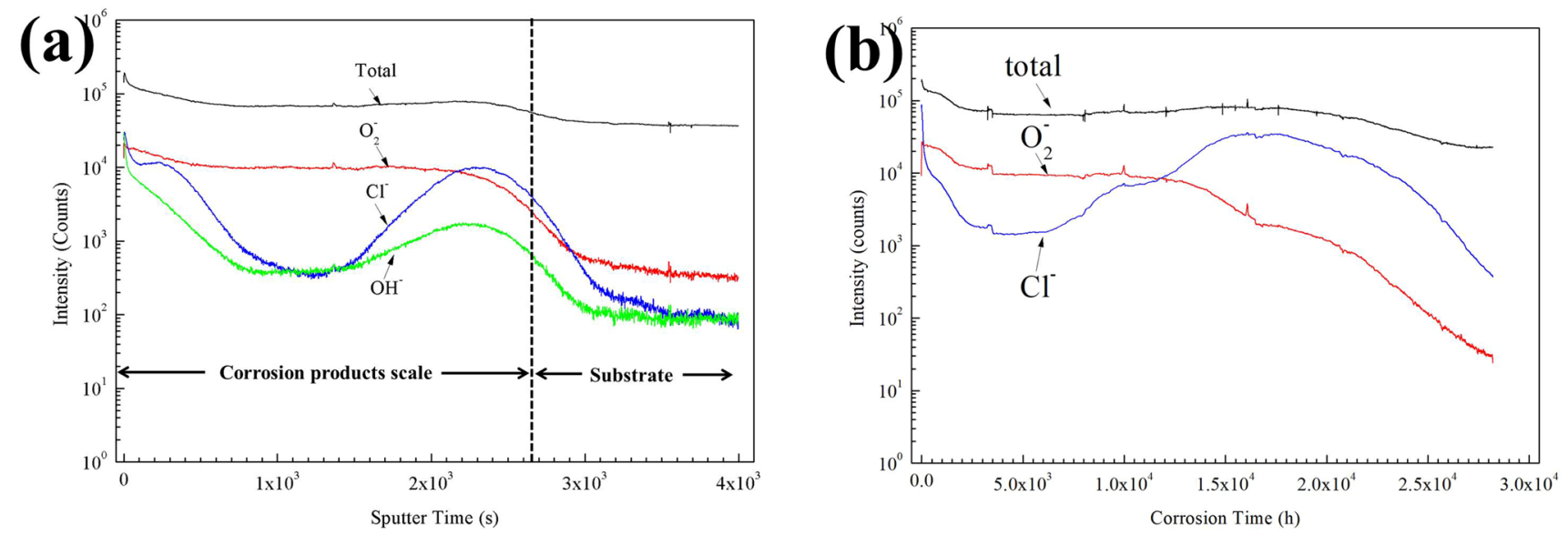

Figure 14. ToF-SIMS sputter depth profiles in the corrosion products scales formed on the pre-oxidized samples under a $\mathrm{NaCl}$ deposit in an atmosphere of humid $\mathrm{O}_{2}$ at $600{ }^{\circ} \mathrm{C}$ for $1 \mathrm{~h}(\mathbf{a})$ and $5(\mathbf{b})$.

\begin{tabular}{|l|l|}
\hline Reaction & $\Delta \mathbf{G}^{\mathbf{}} \mathbf{k J} / \mathbf{m o l}$ \\
\hline $\mathrm{Ti}+\mathrm{O}_{2} \rightarrow \mathrm{TiO}_{2}$ & -785 \\
\hline $4 \mathrm{NaCl}+6 \mathrm{TiO}_{2} \rightarrow \mathrm{Na}_{4} \mathrm{Ti}_{5} \mathrm{O}_{12}+\mathrm{TiCl}_{4}$ & -65 \\
\hline $4 \mathrm{NaCl}+5 \mathrm{TiO}_{2}+2 \mathrm{H}_{2} \mathrm{O} \rightarrow \mathrm{Na}_{4} \mathrm{Ti}_{5} \mathrm{O}_{12}+4 \mathrm{HCl}$ & -195 \\
\hline $\mathrm{TiC}_{4}+2 \mathrm{H}_{2} \mathrm{O} \rightarrow \mathrm{TiO}_{2}+4 \mathrm{HCl}$ & -130 \\
\hline $\mathrm{Ti}+2 \mathrm{HCl} \rightarrow \mathrm{TiCl}_{2}+\mathrm{H}_{2}$ & -174 \\
\hline $\mathrm{Ti}+4 \mathrm{HCl} \rightarrow \mathrm{TiCl}_{4}+2 \mathrm{H}_{2}$ & -256 \\
\hline $2 \mathrm{TiCl}_{2}+2 \mathrm{H}_{2} \mathrm{O}+\mathrm{O}_{2} \rightarrow 2 \mathrm{TiO}_{2}+4 \mathrm{HCl}$ & -905 \\
\hline $2 \mathrm{H}_{2}+\mathrm{O}_{2} \rightarrow 2 \mathrm{H}_{2} \mathrm{O}$ & -399 \\
\hline
\end{tabular}

Table 2. Standard Gibbs free energy changes of reactions at $600{ }^{\circ} \mathrm{C}$. ${ }^{*}$ The $\mathrm{G}^{\mathrm{o}}$ value of $\mathrm{Na}_{4} \mathrm{Ti}_{5} \mathrm{O}_{12}$ was calculated by the first principles. And others were calculated by the HSC Chemistry.

$$
6 \mathrm{TiO}_{2}+4 \mathrm{NaCl}=\mathrm{Na}_{4} \mathrm{Ti}_{5} \mathrm{O}_{12}+\mathrm{TiCl}_{4}
$$

The $\mathrm{TiCl}_{4}$ reacts with $\mathrm{H}_{2} \mathrm{O}$ to form $\mathrm{HCl}$ :

$$
\mathrm{TiCl}_{4}+2 \mathrm{H}_{2} \mathrm{O}=\mathrm{TiO}_{2}+4 \mathrm{HCl}
$$

Then, $\mathrm{HCl}$ reacts with the substrate cyclically:

$$
\begin{gathered}
2 \mathrm{HCl}+\mathrm{Ti}=\mathrm{TiCl}_{2}+\mathrm{H}_{2} \\
4 \mathrm{HCl}+\mathrm{Ti}=\mathrm{TiCl}_{4}+2 \mathrm{H}_{2} \\
2 \mathrm{TiCl}_{2}+\mathrm{O}_{2}+2 \mathrm{H}_{2} \mathrm{O}=2 \mathrm{TiO}_{2}+4 \mathrm{HCl} \\
2 \mathrm{H}_{2}+\mathrm{O}_{2}=2 \mathrm{H}_{2} \mathrm{O}
\end{gathered}
$$

These reactions are thermodynamically spontaneous due to the negative $\Delta \mathrm{G}^{\mathrm{o}}$ at $600{ }^{\circ} \mathrm{C}$, as presented in Table 2 .

As shown in Fig. 3b, in the corrosion product scale there are holes which provide rapid diffusion channels for corrosive species (for example, oxygen, chlorine and water vapor). Meanwhile, a corrosion scale is formed by the outward diffusion of Ti which results in a $15 \mu \mathrm{m}$ loose layer that is observed under the corrosion products. Hence, the corrosion product scale is non-protective and the corrosion of pure Ti is greatly accelerated by solid $\mathrm{NaCl}$ in an $\mathrm{O}_{2}+\mathrm{H}_{2} \mathrm{O}$ environment at $600{ }^{\circ} \mathrm{C}$, which is similar with the observation for several Ti alloy ${ }^{11,18-20}$.

The protection of pre-oxidation scale to the pure Ti. After pre-oxidation in $\mathrm{O}_{2}$ flow for $20 \mathrm{~h}$, a continuous, compact and even oxide scale is formed on the surface (Fig. 2). The pre-oxidation scale is only $\mathrm{TiO}_{2}$ (Fig. 2c) and its thickness is about $1 \mu \mathrm{m}$ (Fig. 2b). Since this scale can protect the substrate, the mass gain of the pre-oxidized samples is small in the dry $\mathrm{O}_{2}$ or humid $\mathrm{O}_{2}$ (Fig. 1).

When pre-oxidized samples are exposed in the presence of solid $\mathrm{NaCl}\left(\mathrm{NaCl}+\mathrm{O}_{2}\right.$ and $\left.\mathrm{NaCl}+\mathrm{H}_{2} \mathrm{O}+\mathrm{O}_{2}\right)$, the mass gain of the pre-oxidized samples is smaller than that of the bare samples (Fig. 1), especially in the incubation period (the mass gain increases slowly). The resulting scale on the pre-oxidized samples (which is compact as 
shown in Figs. 7 and 8) is thinner than that on the bare samples (which is porous as shown in Fig. 3). Thus, the pre-oxidation can protect the pure Ti samples from the corrosion under $\mathrm{NaCl}$ deposit. This is mainly attributed to the compact $\mathrm{TiO}_{2}$ scale formed on the surface in the pre-oxidation (Fig. 2). During the pre-oxidation, the thickness of the formed $\mathrm{TiO}_{2}$ scale is about $1 \mu \mathrm{m}$, and the pre-oxidation scale is larger thicker than the passive film forming on the bare sample. Thus, the $\mathrm{TiO}_{2}$ scale can be a barrier layer for the diffusion of corrosive species (for example, oxygen, water vapor and $\mathrm{HCl}$ ) and reduce the corrosion to a certain extent, especially in the incubation period.

The destruction of pre-oxidation scale. When exposed in humid $\mathrm{O}_{2}$, the pre-oxidized samples suffer a slightly more serious oxidation than when exposed in dry $\mathrm{O}_{2}$ (Fig. 1). This is because $\mathrm{H}_{2} \mathrm{O}$ tends to dissociate at the defects on $\mathrm{TiO}_{2} /(110)$ planes into free $\mathrm{H}$ atoms and $\mathrm{OH}^{-}$groups ${ }^{21-23}$ when the pre-oxidized samples is exposed in humid $\mathrm{O}_{2}$. The papers ${ }^{21,22}$ reported that along the crystal channels in $\mathrm{c}$-axis direction, the diffusion rate of hydrogen is at least one order of magnitude larger than that in the perpendicular direction of c-axis. Thus, the generated hydrogen atoms are more prone to diffuse into $\mathrm{TiO}_{2}$ through the former one. This dissolution of hydrogen in $\mathrm{TiO}_{2}$ will form hydrogen defects, thus the hydrogen can increase the concentration of crystal defects and increase the outward diffusion of $\mathrm{Ti}$ ions ${ }^{23}$. This fast diffusion in the scale causes a larger corrosion rate and hence the hole forms in the oxide scale (Fig. 6), which make the corrosion product scale thicker and more porous (Fig. 6c). Thus, the water vapor slightly reduces the protection of the pre-oxidation scale by forming the $\mathrm{H}$ defects.

From Fig. 1, we can observe the following: (1) after the incubation period, the mass gain of the pre-oxidized samples increases more rapidly when exposed in the presence of the solid $\mathrm{NaCl}\left(\mathrm{NaCl}+\mathrm{O}_{2}\right.$ or $\left.\mathrm{NaCl}+\mathrm{H}_{2} \mathrm{O}+\mathrm{O}_{2}\right)$ than when exposed in the absence of the solid $\mathrm{NaCl}\left(\mathrm{O}_{2}\right.$ or $\left.\mathrm{H}_{2} \mathrm{O}+\mathrm{O}_{2}\right) ;(2)$ after 20 h exposure, the pre-oxidized samples has a larger mass gain under the condition of $\mathrm{NaCl}+\mathrm{O}_{2}$ or $\mathrm{NaCl}+\mathrm{H}_{2} \mathrm{O}+\mathrm{O}_{2}$ than under the condition of $\mathrm{O}_{2}$ or $\mathrm{H}_{2} \mathrm{O}+\mathrm{O}_{2}$. Additionally, we can observe that the corrosion product scale of the pre-oxidized samples is thicker when exposed in the presence of the solid $\mathrm{NaCl}$ (Figs. 7 and 8) than when exposed in the absence of the solid $\mathrm{NaCl}$ (Figs. 5 and 6). Thus, we can claim that the corrosion of the pre-oxidized samples is accelerated by solid $\mathrm{NaCl}$. The fast corrosion and the formation of $\mathrm{Na}_{4} \mathrm{Ti}_{5} \mathrm{O}_{12}$ on the surface (Fig. 9c,d) indicate that the "protective oxide" formed in the pre-oxidation is not completely inert to solid $\mathrm{NaCl}$.

The diffusion of the chlorine in the pre-oxidation scale. The evidence from XRD and SEM/EDX show that $\mathrm{Na}_{4} \mathrm{Ti}_{5} \mathrm{O}_{12}$ formed on the surface (see Figs. 4 and $9 \mathrm{c}, \mathrm{d}$ ). This indicated that the solid $\mathrm{NaCl}$ reacted with the $\mathrm{TiO}_{2}$ scale. Similar observations have been reported for Ti alloy using the same experimental conditions ${ }^{18}$. In that case, it was argued that the fast corrosion in an $\mathrm{O}_{2}+\mathrm{H}_{2} \mathrm{O}$ environment is triggered by titanate formation. Thus, in an $\mathrm{O}_{2}+\mathrm{H}_{2} \mathrm{O}+\mathrm{NaCl}$ environment, the formation of titanate destroys the protective scale formed on the surface, and then the gathered chlorine circularly reacts with the substrate. Thus, for the corrosion of pure $\mathrm{Ti} / \mathrm{Ti}$ alloy in the $\mathrm{NaCl}+\mathrm{H}_{2} \mathrm{O}+\mathrm{O}_{2}$ environment, the chlorine is the main factor.

For the pre-oxidized samples, a thick $\mathrm{TiO}_{2}$ scale is formed on the surface; thus, it takes more time to destroy the protective $\mathrm{TiO}_{2}$ scale by $\mathrm{Na}_{4} \mathrm{Ti}_{5} \mathrm{O}_{12}$ formation and the mass gain changes little during the incubation period (Fig. 1). Furthermore, after the sodium forms $\mathrm{Na}_{4} \mathrm{Ti}_{5} \mathrm{O}_{12}$, the gathered chlorine diffuses inward to the metal/oxide interface (Fig. 14a). Shu et al. ${ }^{18}$ report that the chlorine permeates into the corrosion product scale as molecule, like $\mathrm{HCl}$ or $\mathrm{Cl}_{2}$. For the pre-oxidized samples, a compact $\mathrm{TiO}_{2}$ formed on the surface protects the substrate from the inward diffusion of chlorine and the fast corrosion. Nevertheless, during the incubation period, the chlorine also diffuses into the metal/oxide interface (Fig. 14a) while the $\mathrm{TiO}_{2}$ scale is complete (Fig. 9). This implies that the chlorine cannot be molecule. In our previous work, the chlorine forms Ti-Cl bond in the inner corrosion layer by the dopant $\mathrm{Cl}$ replacing $\mathrm{O}$ in the Ti oxides lattice when Ti60 alloy was exposed in the $\mathrm{NaCl}+\mathrm{H}_{2} \mathrm{O}+\mathrm{O}_{2}$. On the other hand, the diffusion of ion in the $\mathrm{TiO}_{2}$ is fast and some $\mathrm{NaCl}$ is split into ions $\left(\mathrm{Na}^{+}\right.$and $\left.\mathrm{Cl}^{-}\right)$at 600 ${ }^{\circ} \mathrm{C}$. Hence, we think the chlorine permeates into the corrosion product scale as ion $\left(\mathrm{Cl}^{-}\right)$.

As shown in Fig. 14b, when the pre-oxidized samples suffer from severe corrosion in $\mathrm{NaCl}+\mathrm{H}_{2} \mathrm{O}+\mathrm{O}_{2}$, the chlorine is also observed around the metal/oxide interface by SIMS. Additionally, the intensity of chlorine is still large when the intensity of oxygen decreases to a relatively small value. As aforementioned, the substrate locates at the places where the intensity of oxygen is small. Hence, we can infer that the chlorine diffuses into the substrate and directly binds with the metal of the substrate during the fast corrosion. The gathered compound diffuses outward, resulting in the loss of metal in the substrate. After $20 \mathrm{~h}$ exposure, a mass of the metal reacts with the chlorine and diffuses outward, and the inner corrosion layer is formed under the outer corrosion layer (Fig. 8b).

\section{Conclusion}

During the pre-oxidation, a compact and thick $\mathrm{TiO}_{2}$ scale forms on the surface of pure $\mathrm{Ti}$. This $\mathrm{TiO}_{2}$ scale is the barrier layer for the diffusion of corrosive species (for example, oxygen, chlorine, and water vapor), which can protect the substrate from fast corrosion. However, the "protective oxide" is not completely inert to solid $\mathrm{NaCl}$ and the corrosion rate of the pre-oxidized sample is also greatly accelerated by solid $\mathrm{NaCl}$ after an incubation period. During the incubation period, the chlorine, generated in the decomposition of solid $\mathrm{NaCl}$ at $600{ }^{\circ} \mathrm{C}$, diffuses into the oxide/substrate interface as ions to enhance the corrosion rate, and then the residual sodium reacts with the oxide on the surface. After the incubation period, the chlorine diffuses into the substrate and directly reacts with the substrate, resulting in the fast corrosion. 


\begin{tabular}{|l|l|l|l|l|}
\hline Environment & Mass of $\mathbf{~ a C l ~}\left(\mathbf{m g} / \mathbf{c m}^{2}\right)$ & Water pressure $(\mathbf{k P a})$ & Flow rate of $\mathbf{O}_{2}(\mathbf{m L} / \mathbf{m i n})$ & Temperature $\left({ }^{\circ} \mathbf{C}\right)$ \\
\hline $\mathrm{NaCl}+\mathrm{H}_{2} \mathrm{O}+\mathrm{O}_{2}$ & 4.0 & 31 & 140 & 600 \\
\hline $\mathrm{NaCl}+\mathrm{O}_{2}$ & 4.0 & 0 & 140 & 600 \\
\hline $\mathrm{H}_{2} \mathrm{O}+\mathrm{O}_{2}$ & 0 & 31 & 140 & 600 \\
\hline $\mathrm{O}_{2}$ & 0 & 31 & 140 & 600 \\
\hline
\end{tabular}

Table 3. Experimental parameters.

\section{Experiment}

Materials preparation. The material used in this study was pure Ti and the samples were cut into the size of $10 \mathrm{~mm} \times 15 \mathrm{~mm} \times 2.5 \mathrm{~mm}$. Prior to experiments, all samples were mechanically grinded with $800 \# \mathrm{SiC}$ paper, ultrasonically degreased in alcohol for about $20 \mathrm{~min}$, and dried in the air. The bare samples were then exposed in the pure $\mathrm{O}_{2}$ flow at $600{ }^{\circ} \mathrm{C}$ for $20 \mathrm{~h}$ for the pre-oxidization. The surfaces of preheated samples were covered with a layer of $\mathrm{NaCl}$ deposit by repeatedly brushing and drying with saturated $\mathrm{NaCl}$ solution ${ }^{1,6,8,9,18,24}$, until about $4 \pm 0.2 \mathrm{mg} / \mathrm{cm}^{2}$ solid $\mathrm{NaCl}$ was deposited on.

Corrosion experiments. The corrosion tests were carried out in a thermo-balance ${ }^{1,6,8,9,24}$. The continuous mass gain during the corrosion experiment was obtained with a thermo-gravimetric analysis (TGA).

The pure $\mathrm{O}_{2}$ was bubbled into the distilled water with a glass bubbler (when the inner diameter of the tube was about $3.2 \mathrm{~cm}$, the flow rate of pure $\mathrm{O}_{2}$ was about $140 \mathrm{~mL} / \mathrm{min}$ in this study) to produce the test atmosphere (humid $\mathrm{O}_{2}$ ). According to the relationship between the vapor pressure of water and its temperature, we precisely set up the temperature of the distilled water in the glass bubbler to control the amount of the water vapor. In this study, the temperature of the distilled water was about $70{ }^{\circ} \mathrm{C}$, producing about 30.8 vol.\% water vapor. In order to avoid the water vapor condensing inside the thermo-balance, a counter flow of pure $\mathrm{N}_{2}$ was passed through the thermo-balance, whose flow rate was about $400 \mathrm{~mL} / \mathrm{min}$. After the furnace reached $600{ }^{\circ} \mathrm{C}$ and the gas flows of humid $\mathrm{O}_{2}$ as well as pure $\mathrm{N}_{2}$ stabilized, the samples were quickly lowered into the constant temperature zone of the furnace tube.

In this study, the corrosion experiments were respectively carried out under the following four conditions: the first condition was with a solid $\mathrm{NaCl}$ deposit layer in a humid $\mathrm{O}_{2}$ flow at $600{ }^{\circ} \mathrm{C}$ (denoted as $\mathrm{NaCl}+\mathrm{H}_{2} \mathrm{O}+\mathrm{O}_{2}$ ); the second condition was carried out in a humid $\mathrm{O}_{2}$ flow at $600{ }^{\circ} \mathrm{C}$ (denoted as $\mathrm{H}_{2} \mathrm{O}+\mathrm{O}_{2}$ ); the third condition was with a solid $\mathrm{NaCl}$ deposit layer in a dry $\mathrm{O}_{2}$ flow at $600{ }^{\circ} \mathrm{C}$ (denoted as $\mathrm{NaCl}+\mathrm{O}_{2}$ ); and the fourth condition was carried out in a dry $\mathrm{O}_{2}$ flow at $600{ }^{\circ} \mathrm{C}$ (denoted as $\mathrm{O}_{2}$ ). We present the explicit environmental parameters in Table 3.

Morphologies and chemical composition analysis. The surface morphologies and the cross-sectional morphologies of corrosion products scale were collected by SEM-EDS. The chemical composition of corrosion products was identified by XRD.

To protect the oxide scale from fracture and spall during the metallographic preparation, the corroded samples were wrapped into a thin nickel foil by electroless plating and were embedded into the epoxy resin. Then, the corroded samples were grinded to 3000 grit with SiC paper. Finally, the corroded samples were polished with diamond paste. The samples were washed with distilled water to remove the residual solid $\mathrm{NaCl}$, and then dried in air, before surface investigation by SEM. Under the condition of $\mathrm{H}_{2} \mathrm{O}+\mathrm{O}_{2}$ and $\mathrm{O}_{2}$, the mass gains of the pre-oxidized sample were very small (Fig. 1) and the corrosion was minor. The surface and the cross-sectional morphologies after a longer corrosion time $(100 \mathrm{~h})$ were investigated.

Time of flight-secondary ion mass spectrometry, ToF-SIMS. The pre-oxidized samples were first exposed in either $\mathrm{NaCl}+\mathrm{H}_{2} \mathrm{O}+\mathrm{O}_{2}$ or $\mathrm{NaCl}+\mathrm{O}_{2}$. Then, they are ultrasonically washed with distilled water to remove the residual solid $\mathrm{NaCl}$. After the pre-oxidized samples were further dried in the air, they were analyzed using a ToF-SIMS5 instrument (ION-TOF GmbH), which allowed parallel mass registration with high sensitivity and high mass resolution. A cesium liquid-metal ion (LMI) gun at $20 \mathrm{keV}$ beam energy was used for spatially resolved ToF-SIMS analysis.

Received: 14 November 2019; Accepted: 22 June 2020

Published online: 01 October 2020

\section{References}

1. Shu, Y., Wang, F. \& Wu, W. Corrosion behavior of pure $\mathrm{Cr}$ with a solid $\mathrm{NaCl}$ deposit in $\mathrm{O}_{2}$ plus water vapor. Oxid. Met. 54, 457-471. https://doi.org/10.1023/a:1004690518225 (2000).

2. Liu, L., Li, Y., Zeng, C. \& Wang, F. Electrochemical impedance spectroscopy (EIS) studies of the corrosion of pure Fe and Cr at $600{ }^{\circ} \mathrm{C}$ under solid $\mathrm{NaCl}$ deposit in water vapor. Electrochim. Acta 51, 4736-4743. https://doi.org/10.1016/j.electacta.2006.01.033 (2006).

3. Tang, Y., Liu, L., Li, Y. \& Wang, F. The electrochemical corrosion mechanisms of pure $\mathrm{Cr}$ with $\mathrm{NaCl}$ deposit in water vapor at 600 ${ }^{\circ}$ C. J. Electrochem. Soc. 158, C237. https://doi.org/10.1149/1.3596167 (2011).

4. Tang, Y., Liu, L., Li, Y. \& Wang, F. Evidence for the occurrence of electrochemical reactions and their interaction with chemical reactions during the corrosion of pure $\mathrm{Fe}$ with solid $\mathrm{NaCl}$ deposit in water vapor at $600{ }^{\circ} \mathrm{C}$. Electrochem. Commun. 12, 191-193. https://doi.org/10.1016/j.elecom.2009.11.021 (2010). 
5. Tang, Y., Liu, L., Fan, L., Li, Y. \& Wang, F. The corrosion behavior of pure iron under solid $\mathrm{Na}_{2} \mathrm{SO}_{4}$ deposit in wet oxygen flow at $500^{\circ} \mathrm{C}$. Materials 7, 6144-6157. https://doi.org/10.3390/ma7096144 (2014).

6. Wang, F. \& Shu, Y. Influence of $\mathrm{Cr}$ content on the corrosion of $\mathrm{Fe}-\mathrm{Cr}$ alloys: the synergistic effect of $\mathrm{NaCl}$ and water vapor. Oxid. Met. 59, 201-214. https://doi.org/10.1023/A:1023083309041 (2003).

7. 7Pujilaksono, B. et al. Oxidation of binary $\mathrm{FeCr}$ alloys $\left(\mathrm{Fe}-2.25 \mathrm{Cr}, \mathrm{Fe}-10 \mathrm{Cr}, \mathrm{Fe}-18 \mathrm{Cr}\right.$ and $\mathrm{Fe}-25 \mathrm{Cr}$ ) in $\mathrm{O}_{2}$ and in $\mathrm{O}_{2}+\mathrm{H}_{2} \mathrm{O}$ environment at $600{ }^{\circ} \mathrm{C}$. Oxidation of Metals75, 183-207, https://doi.org/10.1007/s11085-010-9229-z (2011).

8. Shu, Y., Wang, F. \& Wu, W. Synergistic effect of $\mathrm{NaCl}$ and water vapor on the corrosion of $1 \mathrm{Cr}-11 \mathrm{Ni}-2 \mathrm{~W}-2 \mathrm{Mo}-\mathrm{V}$ steel at $500-700$ ${ }^{\circ}$ C. Oxid. Met. 51, 97-110. https://doi.org/10.1023/a:1018854202982 (1999).

9. Wang, F., Geng, S. \& Zhu, S. Corrosion behavior of a sputtered K38G nanocrystalline coating with a solid $\mathrm{NaCl}$ deposit in wet oxygen at 600 to $700{ }^{\circ}$ C. Oxid. Met. 58, 185-195. https://doi.org/10.1023/a:1016072726338 (2002).

10. Fan, L. et al. Corrosion behavior of pure Ti under a solid $\mathrm{NaCl}$ deposit in a wet oxygen flow at 600 degrees C. Metals 6, 11. https ://doi.org/10.3390/met6040072 (2016).

11. 11Fan, L. et al. Corrosion behavior of Ti60 alloy under a solid $\mathrm{NaCl}$ deposit in wet oxygen flow at 600 degrees C. Scientific Reports6, https://doi.org/10.1038/srep29019 (2016).

12. Pettersson, J., Asteman, H., Svensson, J. E. \& Johansson, L. G. KCl induced corrosion of a 304-type austenitic stainless steel at 600 ${ }^{\circ} \mathrm{C}$; The role of potassium. Oxid. Met. 64, 23-41. https://doi.org/10.1007/s11085-005-5704-3 (2005).

13. Pettersson, C., Pettersson, J., Asteman, H., Svensson, J. E. \& Johansson, L. G. KCl-induced high temperature corrosion of the austenitic Fe-Cr-Ni alloys 304L and Sanicro 28 at $600^{\circ} \mathrm{C}$. Corros. Sci. 48, 1368-1378. https://doi.org/10.1016/j.corsci.2005.05.018 (2006).

14. Pettersson, C., Johansson, L. G. \& Svensson, J. E. The influence of small amounts of $\mathrm{KCl}(\mathrm{s})$ on the initial stages of the corrosion of alloy sanicro 28 at $600{ }^{\circ} \mathrm{C}$. Oxid. Met. 70, 241-256. https://doi.org/10.1007/s11085-008-9118-x (2008).

15. Jonsson, T. et al. The influence of $\mathrm{KCl}$ on the corrosion of an austenitic stainless steel (304L) in oxidizing humid conditions at 600 ${ }^{\circ} \mathrm{C}$ : a microstructural study. Oxid. Met. 72, 213-239. https://doi.org/10.1007/s11085-009-9156-z (2009).

16. Pettersson, J., Svensson, J. E. \& Johansson, L. G. KCl-Induced corrosion of a 304-type austenitic atainless ateel in $\mathrm{O}_{2}$ and in $\mathrm{O}_{2}+$ $\mathrm{H}_{2} \mathrm{O}$ environment: the influence of temperature. Oxid. Met. 72, 159-177. https://doi.org/10.1007/s11085-009-9153-2 (2009).

17. 17Jonsson, T., Folkeson, N., Svensson, J. E., Johansson, L. G. \& Halvarsson, M. An ESEM in situ investigation of initial stages of the $\mathrm{KCl}$ induced high temperature corrosion of a Fe-2.25Cr-1Mo steel at 400 degrees C. Corrosion Science53, 2233-2246, https:// doi.org/10.1016/j.corsci.2011.03.007 (2011).

18. Shu, Y., Wang, F. \& Wu, W. Corrosion behavior of Ti60 alloy coated with a solid $\mathrm{NaCl}$ deposit in $\mathrm{O}_{2}$ plus water vapor at 500-700 ${ }^{\circ}$ C. Oxid. Met. 52, 463-473. https://doi.org/10.1023/a:1018864216554 (1999).

19. Dumas, P. \& Stjohn, C. Nacl-induced accelerated oxidation of a titanium alloy. Oxid. Met. 10, 127-134. https://doi.org/10.1007/ Bf00614242 (1976)

20. Yao, Z. \& Marck, M. NaCl-induced hot corrosion of a titanium aluminide alloy. Mater. Sci. Eng., A 192-193, 994-1000. https:// doi.org/10.1016/0921-5093(95)03345-9 (1995).

21. Johnson, O. W., Paek, S. H. \& Deford, J. W. diffusion of h and d in TIO2 - suppression of internal fields by isotope-exchange. J. Appl. Phys. 46, 1026-1033. https://doi.org/10.1063/1.322206 (1975).

22. Fowler, J. D., Chandra, D., Elleman, T. S., Payne, A. W. \& Verghese, K. T Diffusion in AL2O3 and BEO/D BEO. J. Am. Ceram. Soc. 60, 155-161. https://doi.org/10.1111/j.1151-2916.1977.tb15493.x (1977).

23. Douglass, D. L., Kofstad, P., Rahmel, A. \& Wood, G. C. International workshop on high-temperature corrosion. Oxid. Met. 45, 529-620. https://doi.org/10.1007/bf01046850 (1996).

24. Wang, C., Jiang, F. \& Wang, F. Corrosion inhibition of 304 stainless steel by nano-sized Ti/silicone coatings in an environment containing $\mathrm{NaCl}$ and Water Vapor at $400-600^{\circ} \mathrm{C}$. Oxid. Met. 62, 1-13. https://doi.org/10.1023/B:OXID.0000038782.77162.5b (2004).

\title{
Acknowledgments
}

The investigation is supported by the National Key Research and Development Program of China (2017YFF0210406), the Shanxi National Science Foundation (2019JQ-213) and the Basic Research and Strategic Reserve Technology Research Fund (project of China National Petroleum Corporation) (2018Z-01).

\section{Author contributions}

L.F. designed and performed experiment. L.F., L.L., C.X.Y, A.Q.F, J.T.Y, F.H.W. and Y.L. discussed and analyzed data. L.F. and L.L. wrote the manuscript. L.L., Y.H.L, H.W revised the paper.

\section{Competing interests}

The authors declare no competing interests.

\section{Additional information}

Correspondence and requests for materials should be addressed to L.L.

Reprints and permissions information is available at www.nature.com/reprints.

Publisher's note Springer Nature remains neutral with regard to jurisdictional claims in published maps and institutional affiliations.

\begin{abstract}
Open Access This article is licensed under a Creative Commons Attribution 4.0 International License, which permits use, sharing, adaptation, distribution and reproduction in any medium or format, as long as you give appropriate credit to the original author(s) and the source, provide a link to the Creative Commons licence, and indicate if changes were made. The images or other third party material in this article are included in the article's Creative Commons licence, unless indicated otherwise in a credit line to the material. If material is not included in the article's Creative Commons licence and your intended use is not permitted by statutory regulation or exceeds the permitted use, you will need to obtain permission directly from the copyright holder. To view a copy of this licence, visit http://creativecommons.org/licenses/by/4.0/.
\end{abstract}

(C) The Author(s) 2020 